\title{
TRAJECTORY ANALYSIS
}

The following diagrams show the 12 hour and 7 day back trajectories for the 11 flights analysed. Diagram names reflect the UST at time of air mass arrival and the flights to which they refer can be determined from Table 1 below. The following colour coding is used: red - $250 \mathrm{~m}$ arrival height; yellow - $750 \mathrm{~m}$ arrival height; green - $1500 \mathrm{~m}$ arrival height; magenta - $3000 \mathrm{~m}$ arrival height. Trajectories are shown not only for the RAMS model grid cell closest to the point of measurement, but also for air masses arriving at adjacent grid cells.

\section{Table 1.}

Details for all 14 flight undertaken, showing the local times of the measurement spirals (UST - 4hrs) as well as trajectory codes (supplementary information), and the day or night time integral period(s) to which the flights relate.

\begin{tabular}{|lccll|l|}
\hline \multicolumn{1}{|c}{ Flight No } & Start Spiral & $\begin{array}{c}\text { End Spiral } \\
\text { Claire-II-3 }\end{array}$ & Trajectory & Day "Period" & "Night Period" \\
Claire-II-4 & $07 / 07 / 200110: 08$ & $07 / 07 / 200110: 28$ & & & \\
Claire-II-5 & $08 / 07 / 200116: 06$ & $07 / 07 / 2001$ & $16: 23$ & 07072030 & \\
& & $08 / 07 / 200109: 45$ & 07081330 & \\
Claire-II-6 & $10 / 07 / 200115: 43$ & $10 / 07 / 200116: 19$ & Not made & \\
Claire-II-7 & $11 / 07 / 200109: 34$ & $11 / 07 / 200109: 51$ & Not made & \\
Claire-II-8 & $11 / 07 / 200115: 37$ & $11 / 07 / 200115: 54$ & Figure 1 & \\
Claire-II-9 & $12 / 07 / 200109: 23$ & $12 / 07 / 200109: 42$ & Figure 1 & \\
& & & & \\
Claire-II-13 & $16 / 07 / 200115: 58$ & $16 / 07 / 200116: 13$ & 07162000 & \\
Claire-II-14 & $17 / 07 / 200109: 43$ & $17 / 07 / 200110: 02$ & 07171400 \\
Claire-II-15 & $17 / 07 / 200115: 18$ & $17 / 07 / 200115: 42$ & 07172000 & \\
Claire-II-16 & $18 / 07 / 200109: 26$ & $18 / 07 / 200109: 43$ & 07181400 & \\
Claire-II-17 & $18 / 07 / 200116: 12$ & $18 / 07 / 200116: 32$ & 07182000 & \\
& & & & \\
Claire-II-20 & $20 / 07 / 200111: 17$ & $20 / 07 / 200111: 36$ & 07201400 & \\
Claire-II-21 & $20 / 07 / 200114: 43$ & $20 / 07 / 200115: 02$ & 07202000 & \\
\hline
\end{tabular}




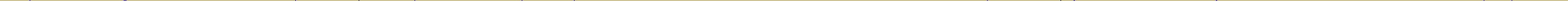




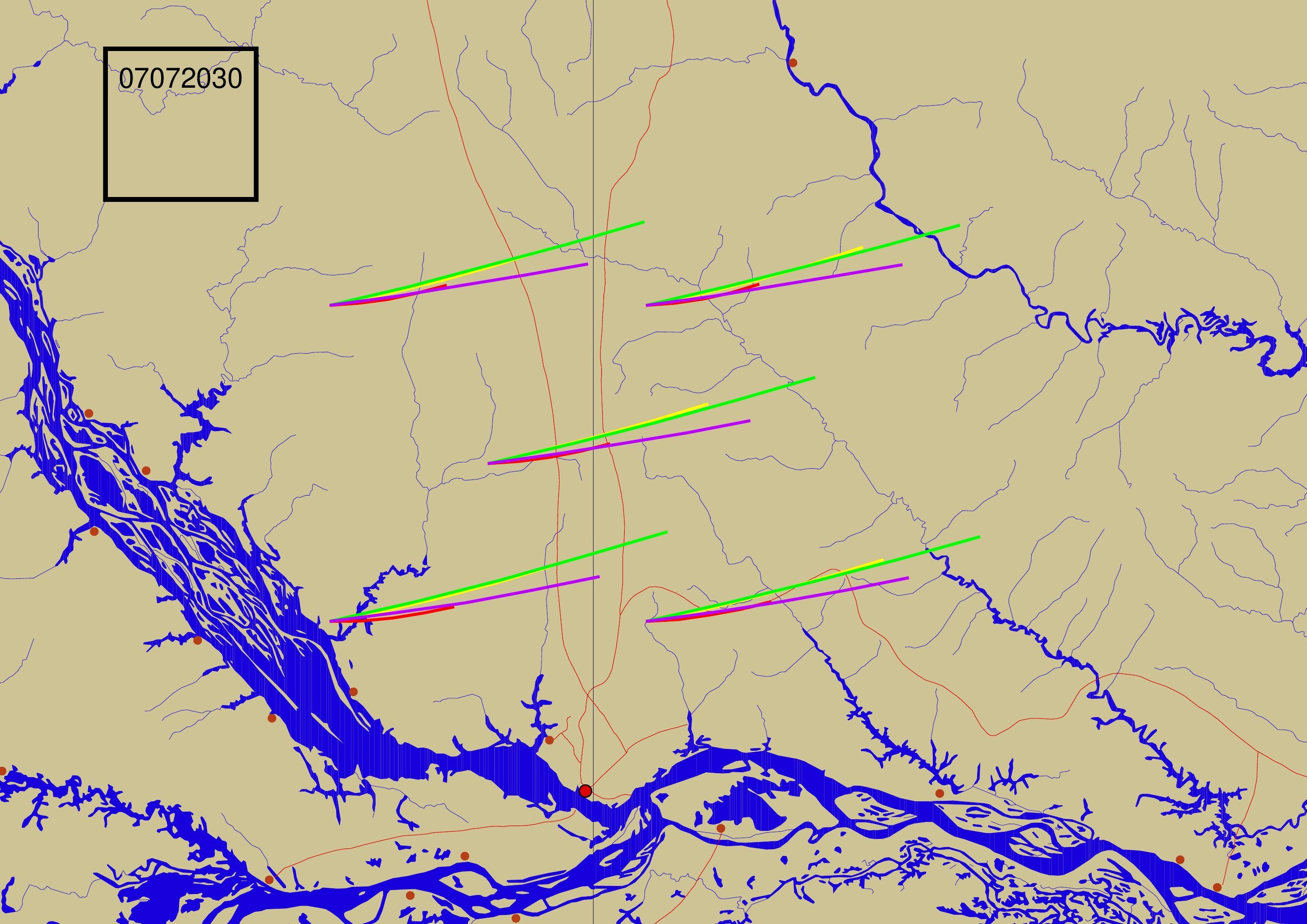




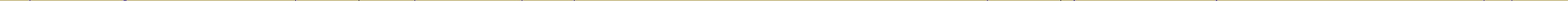




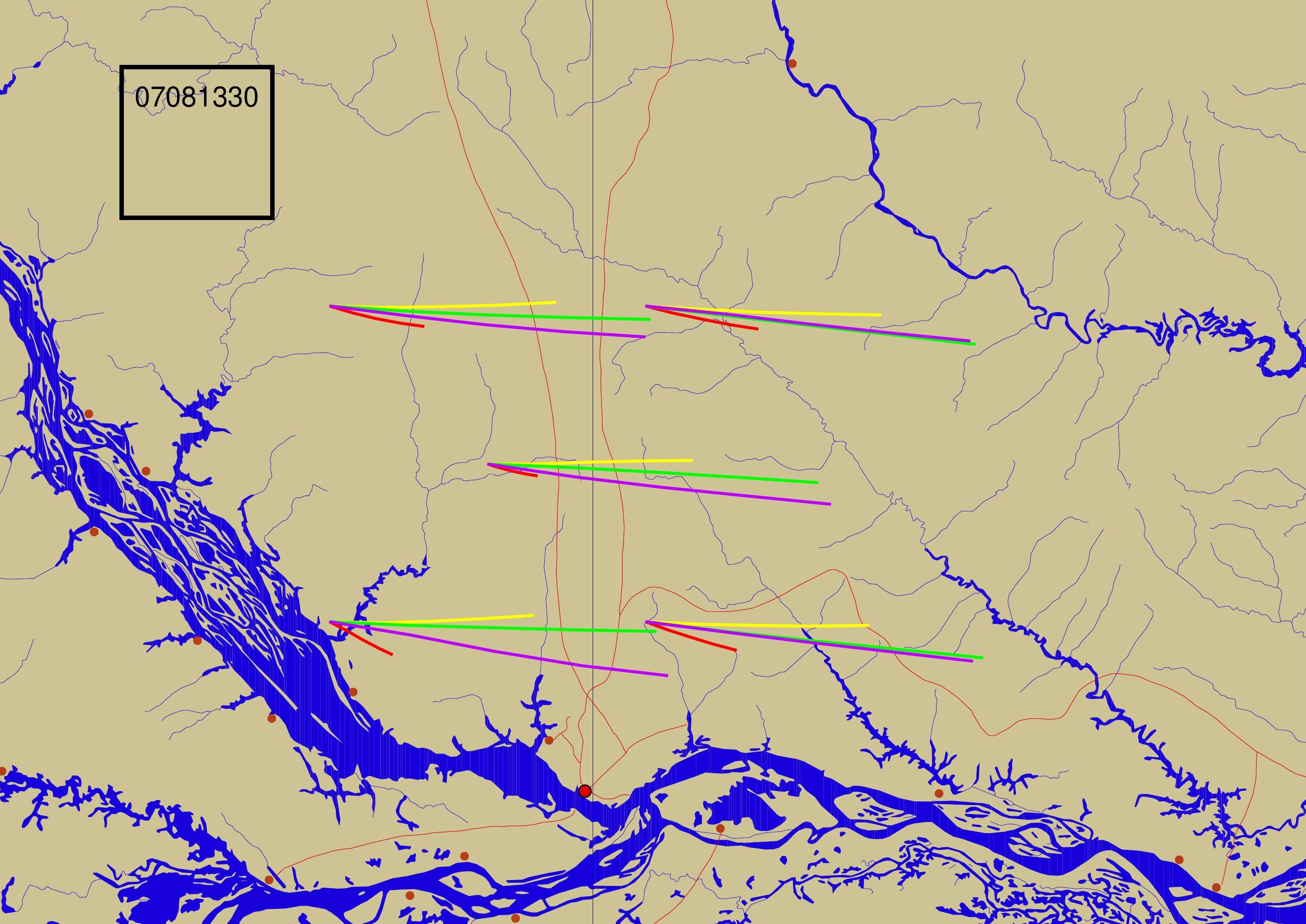




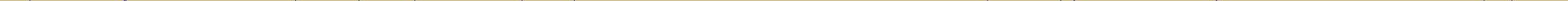




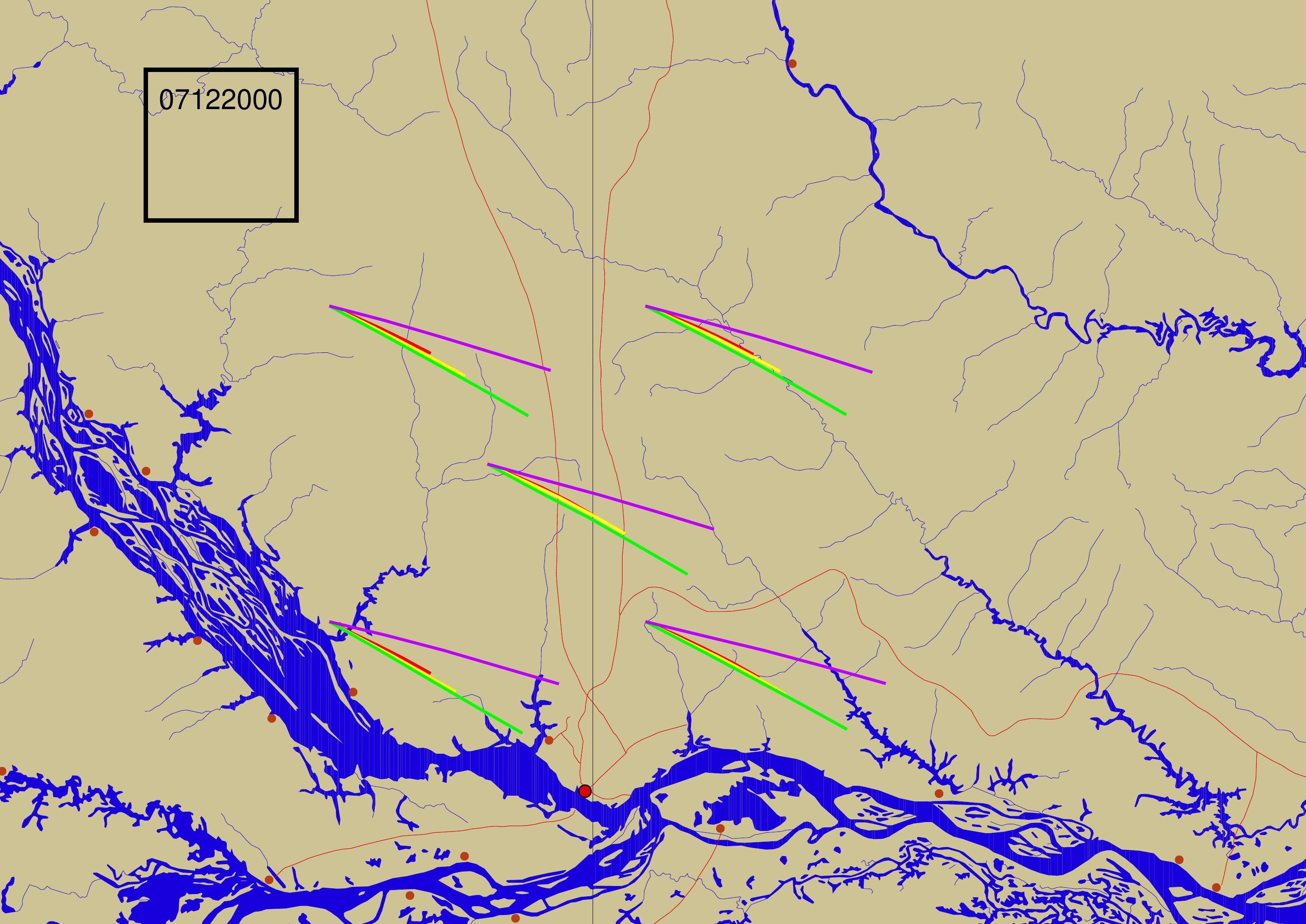




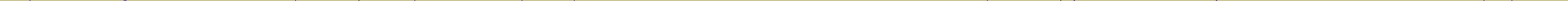




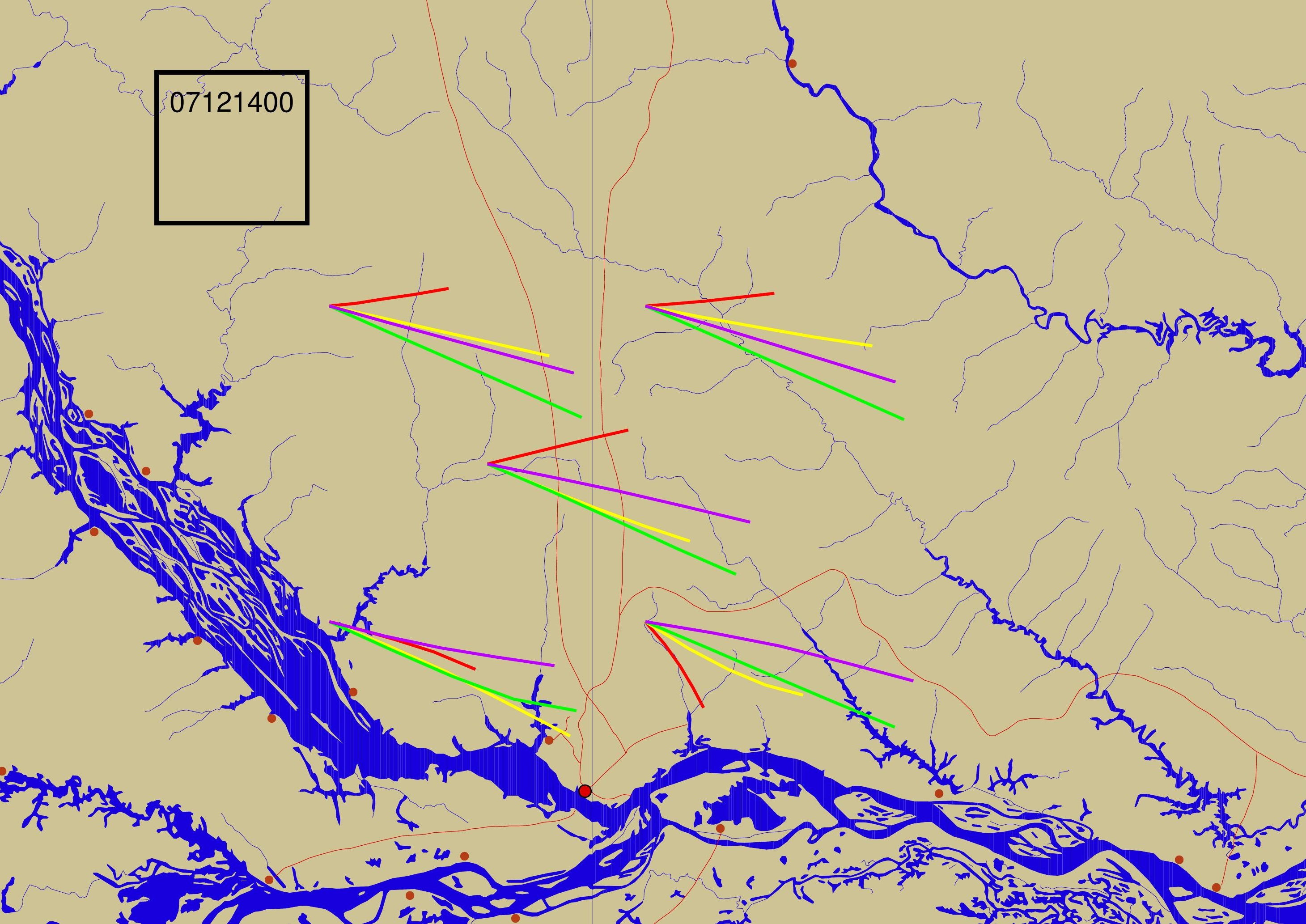




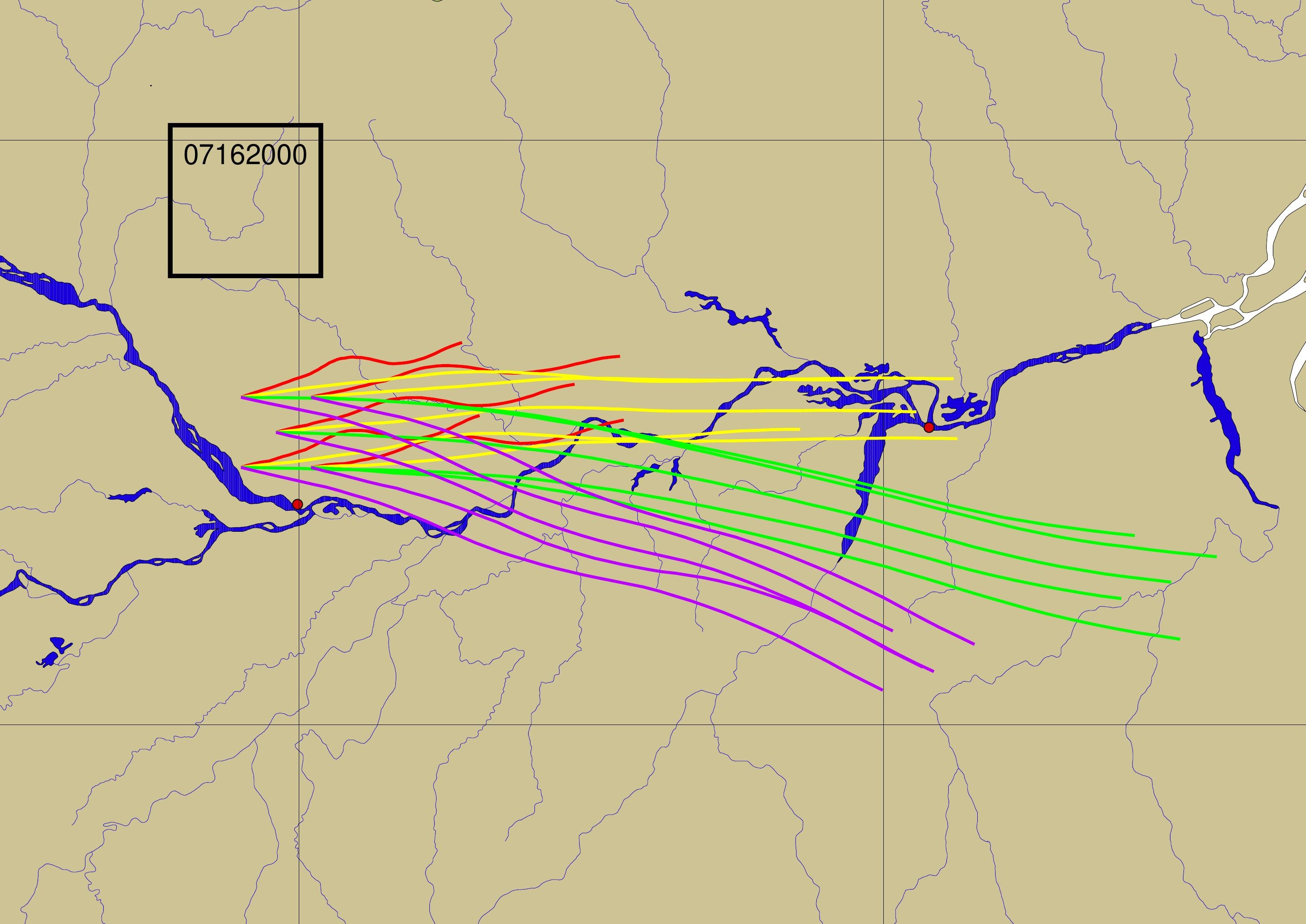




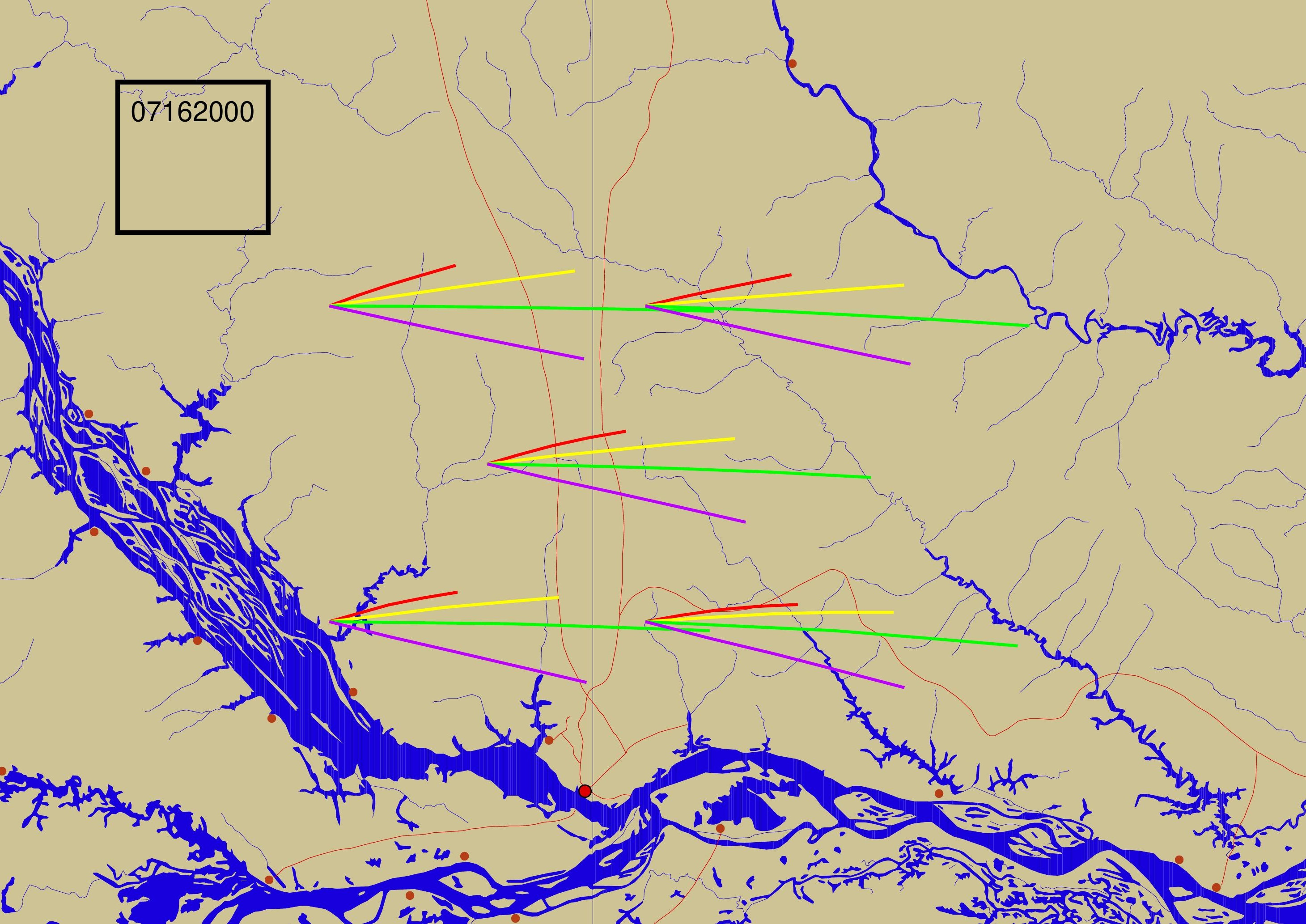




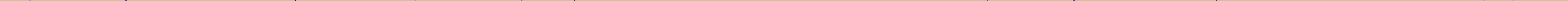




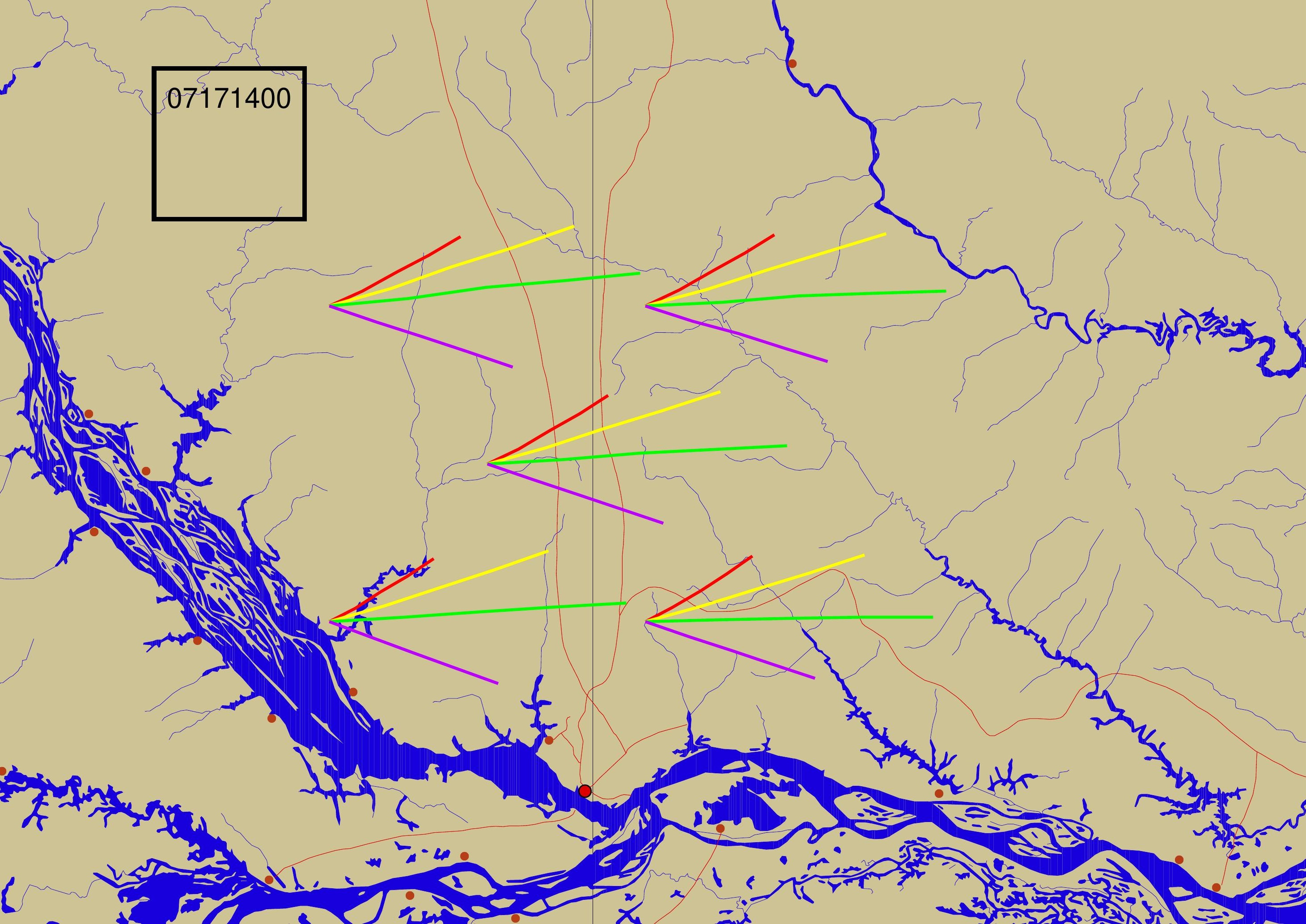




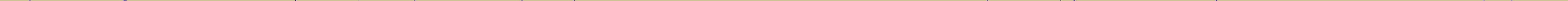




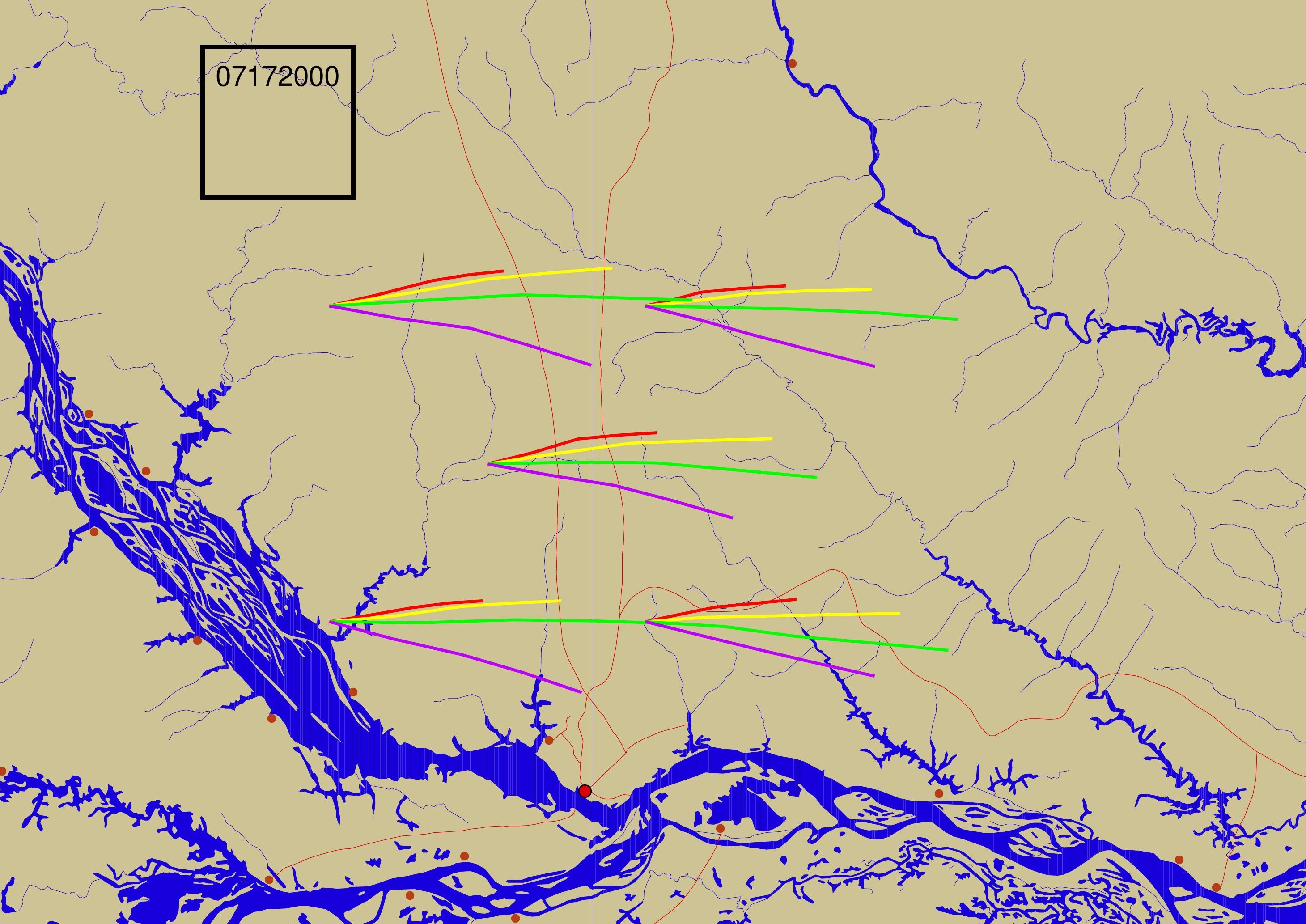




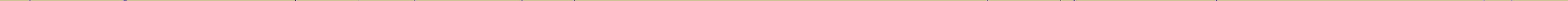




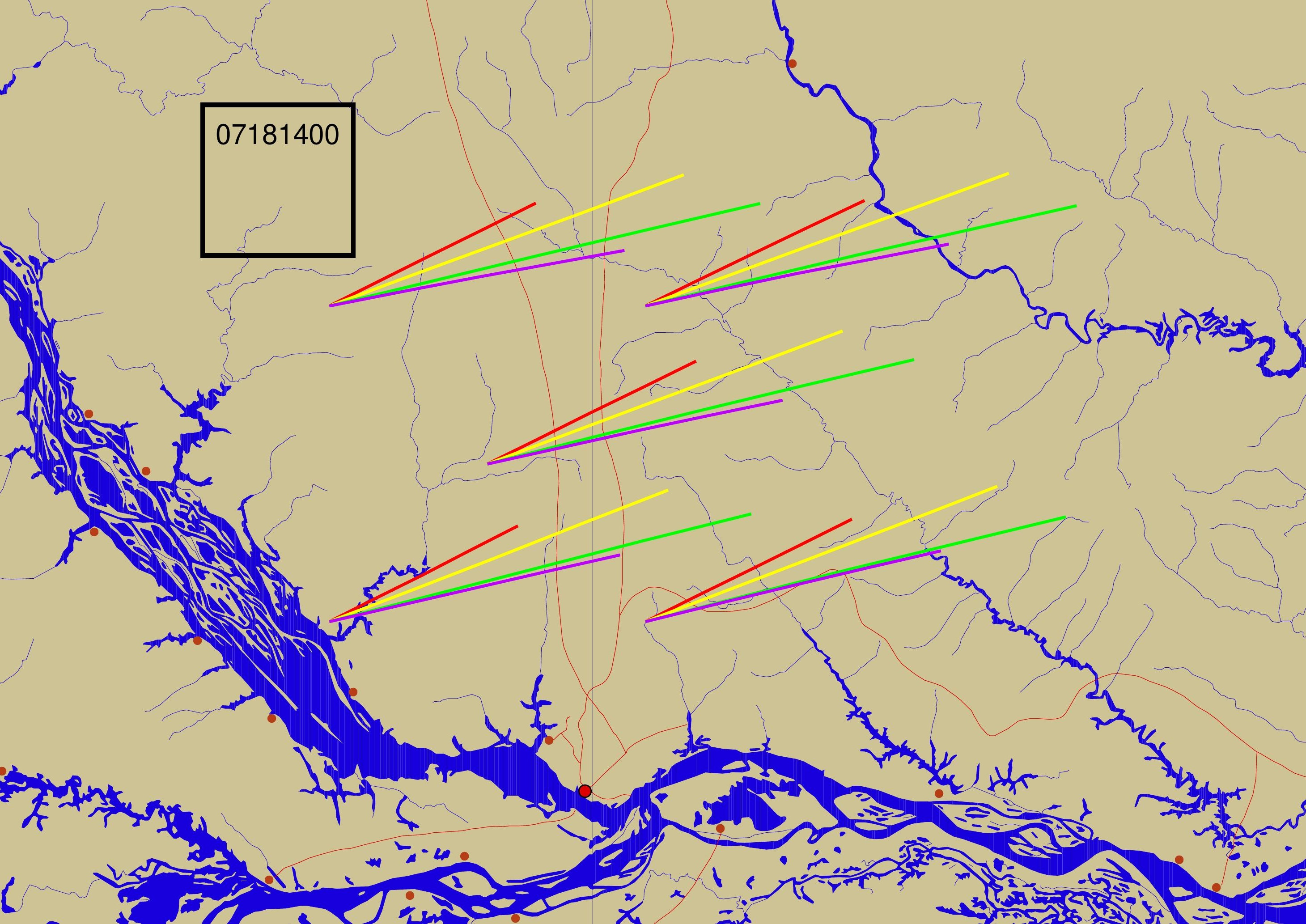




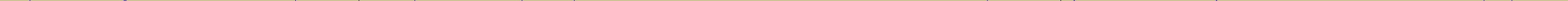




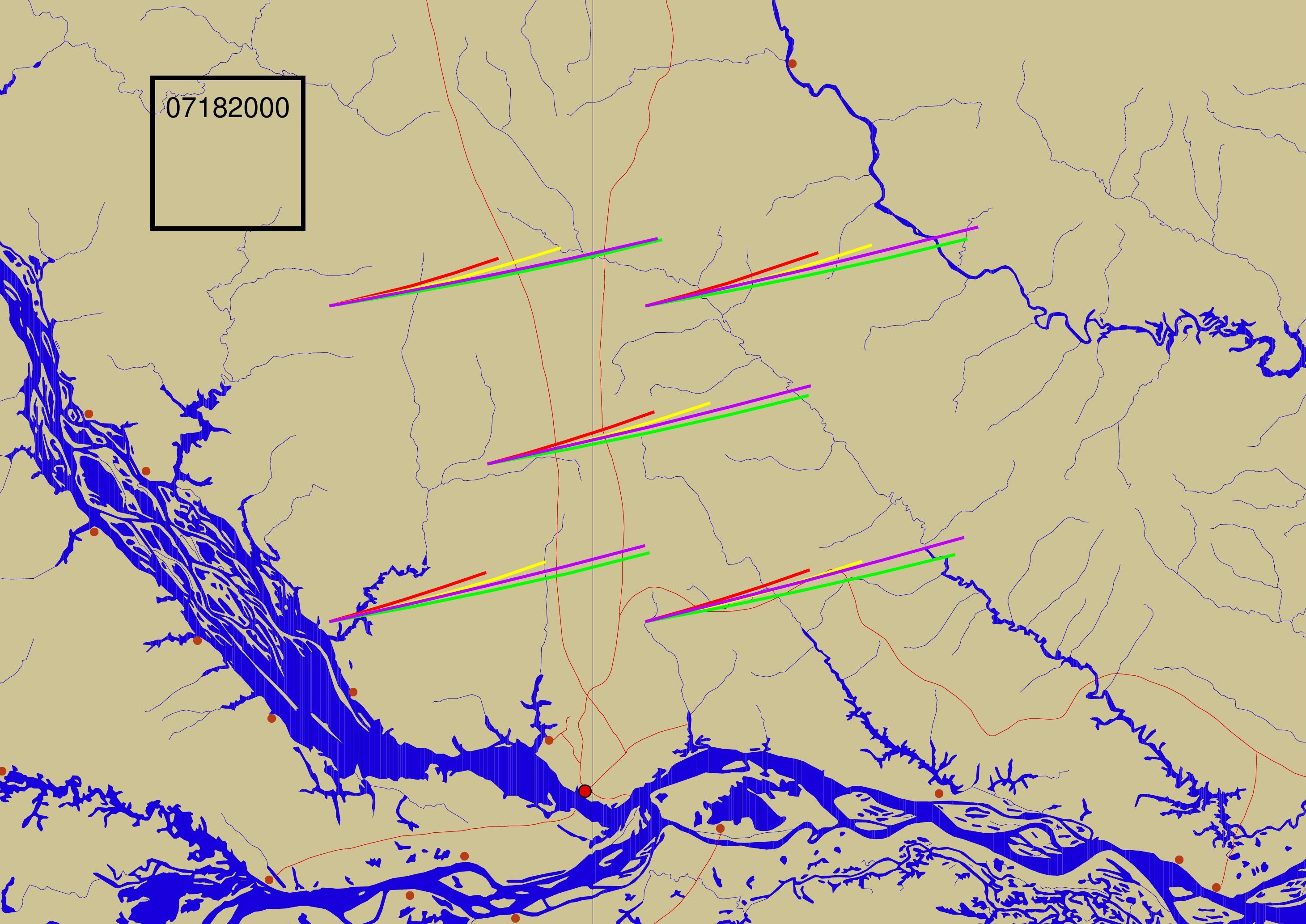




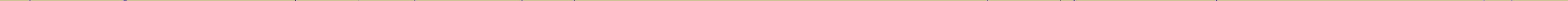




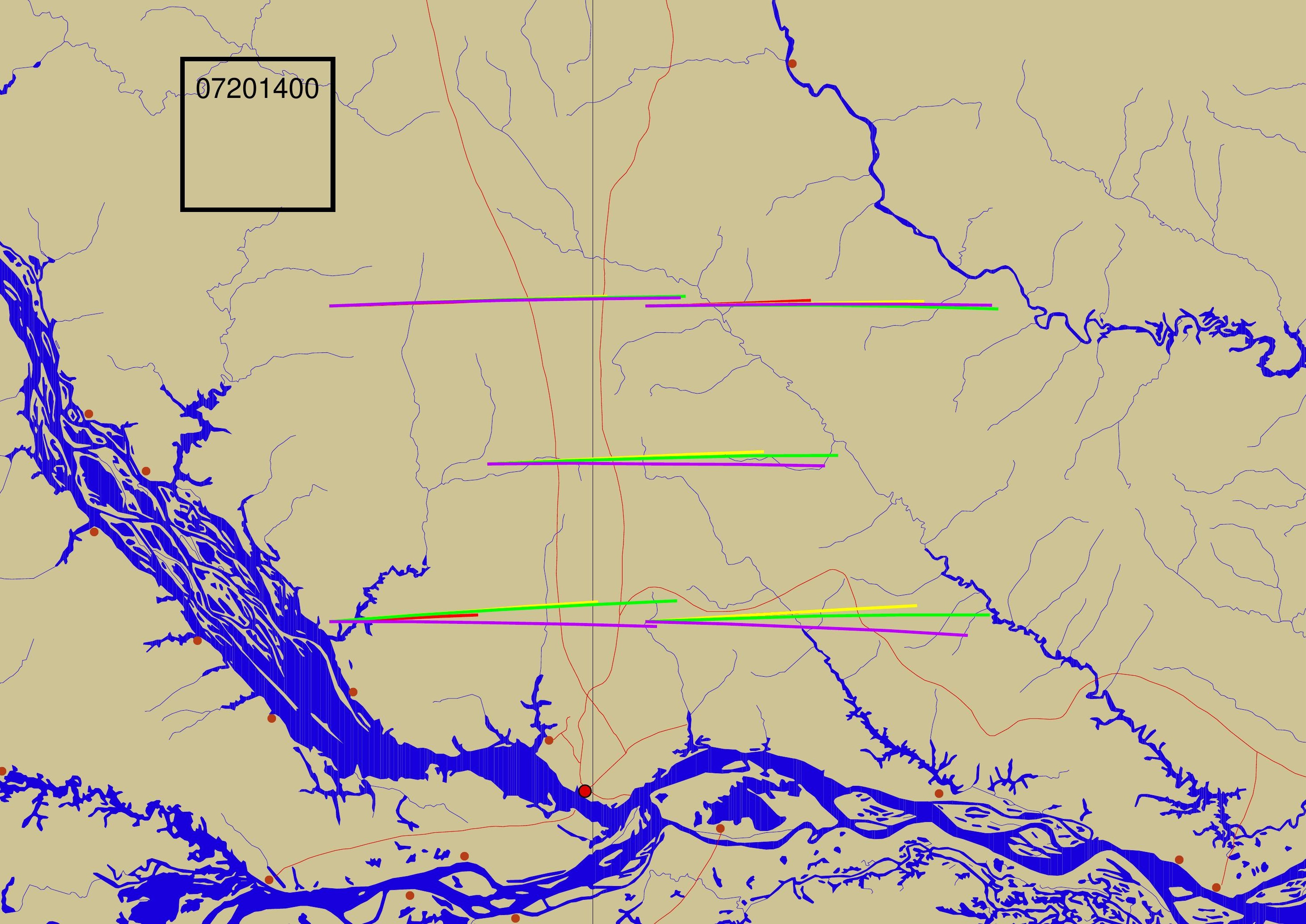




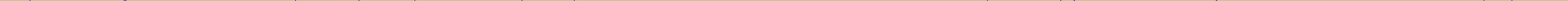




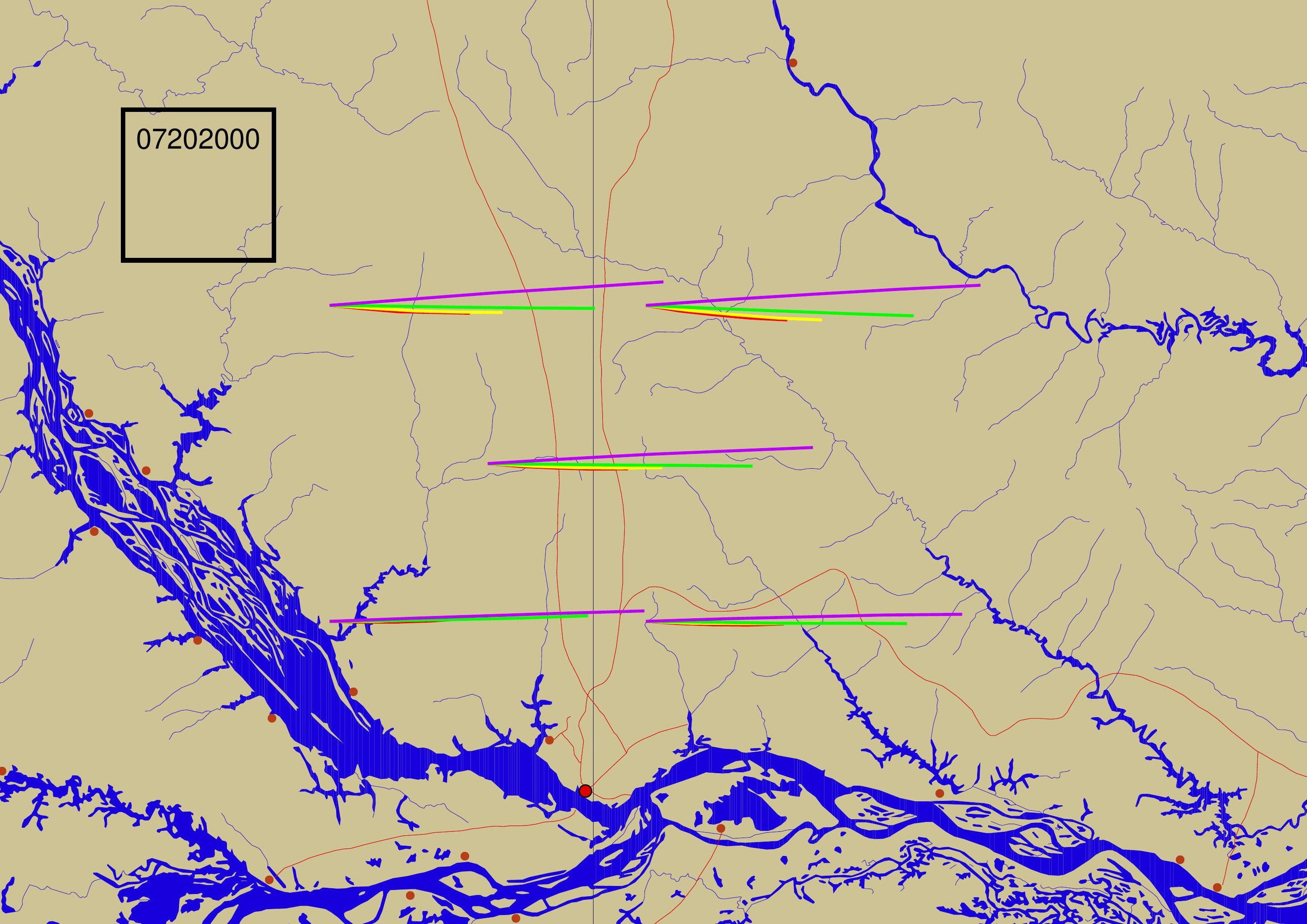

